\title{
Balloon-expandable transcatheter aortic valve implantation with or without pre- dilation - results of a meta-analysis of 3 multicenter registries
}

\author{
Jannik Ole Ashauer ${ }^{1}$, Nikolaos Bonaros ${ }^{2}$, Markus Kofler ${ }^{2}$, Gerhard Schymik $^{3}$, Christian Butter ${ }^{4}$, Mauro Romano ${ }^{5}$, \\ Vinayak Bapat ${ }^{6}$, Justus Strauch ${ }^{7}$, Holger Schröfel ${ }^{8}$, Andreas Busjahn $^{9}$, Cornelia Deutsch $^{10}$, Peter Bramlage ${ }^{10^{*}}$ (D), \\ Jana Kurucova ${ }^{11}$, Martin Thoenes ${ }^{12}$, Stephan Baldus ${ }^{1}$ and Tanja K. Rudolph ${ }^{1,13}$
}

\begin{abstract}
Background: To evaluate the outcomes of transcatheter aortic valve implantation (TAVI) without balloon aortic valvuloplasty (BAV) in a real-world setting through a patient-level meta-analysis.

Methods: The meta-analysis included patients of three European multicenter, prospective, observational registry studies that compared outcomes after Edwards SAPIEN 3 or XT TAVI with $(n=339)$ or without $(n=355)$ BAV. Unadjusted and adjusted pooled odds ratios (with 95\% confidence intervals) were calculated for procedural and 30-day outcomes.

Results: Median procedural time was shorter in the non-BAV group than in the BAV group (73 versus 93 min, $p=0.001$ ), as was median fluoroscopy time (7 versus $11 \mathrm{~min}, p=0.001$ ). Post-delivery balloon dilation ( $15.5 \%$ versus $22.4 \%, p=0.02$ ) and catecholamine use (9.0\% vs. $17.9 \% ; p=0.016)$ was required less often in the non-BAV group than in the BAV group with the difference becoming insignificant after multiple adjustment. There was a reduced risk for periprocedural atrioventricular block during the intervention ( $1.4 \%$ versus $4.1 \%, p=0.035)$ which was non-significant after adjustment. The rate of moderate/severe paravalvular regurgitation post-TAVI was $0.6 \%$ in the no-BAV group versus $2.7 \%$ in the BAV group. There were no between-group differences in the risk of death, stroke or other adverse clinical outcomes at day 30. Conclusions: This patient-level meta-analysis of real-world data indicates that TAVI performed without BAV is advantageous as it has an adequate device success rate, reduced procedure time and no adverse effects on short-term clinical outcomes.
\end{abstract}

Keywords: Transcatheter aortic valve implantation, Balloon aortic valvuloplasty, Pre-dilation, Aortic stenosis

\section{Background}

The conventional approach for transcatheter aortic valve implantation (TAVI) includes pre-dilation balloon aortic valvuloplasty (BAV) to help estimate prosthetic valve size, facilitate delivery of the TAVI catheter across the valve, optimize positioning and expansion of the prosthetic valve [1-4]. BAV can also be associated with adverse effects, however, such as hemodynamic instability, arrhythmia necessitating permanent pacemaker implantation, embolic

\footnotetext{
* Correspondence: peter.bramlage@ippmed.de

${ }^{10}$ Institute for Pharmacology and Preventive Medicine, Bahnhofstrasse 20,

49661 Cloppenburg, Germany

Full list of author information is available at the end of the article
}

events and stroke $[1,4-8]$. Consequently, TAVI is increasingly being performed without BAV $[9,10]$. Clinical studies of TAVI without BAV (direct TAVI) have provided encouraging pivotal results $[11,12]$. Several subanalyses of larger registry studies later also suggested that direct TAVI is associated with good procedural results and clinical outcomes $[9,10,13,14]$. To explore this topic further for balloon expandable valves is important for the following reasons: 1) Penetration of the calcified aortic valves is more cumbersome with balloon-expandable than with self-expanding valves due to the balloon and the annular skirt; 2) After successful implantation there is decreased need for postimplant dilatation (circular shape of the valve, lower rates 
of PV-leaks); 3) A limited balloon inflation can facilitate smooth introduction of the valve into the annulus.

To address this lack of data, three prospective, multicenter, registry studies evaluated TAVI using the balloonexpandable Edwards SAPIEN prosthetic valves, with and without BAV, and found that direct TAVI was feasible, safe and provided adequate efficacy in a real-world setting [1517] (Schymik G, Rudolph TK, Jacobshagen C, Rothe J, Treede H, Kerber S, Frank D, Sykorova L, Okamoto M, Thoenes M, et al. Balloon-expandable transfemoral transcatheter aortic valve implantation with or without predilation - findings from the EASE-IT TF multicentre registry, submitted). A meta-analysis of these three studies has now been conducted to provide additional information on the use of TAVI without BAV in a real-world setting.

\section{Methods}

\section{Study characteristics}

All three studies included in the meta-analysis were multicenter, prospective, observational registry studies conducted under the guidance of the Institute for Pharmacology and Preventive Medicine (Cloppenburg, Germany). Full details of the design and methodology for each study have been reported previously [18-20]. EASEIT TF recruited patients undergoing transfemoral (TF) TAVI from 10 sites in Germany [19], EASE-IT TA recruited patients undergoing transapical (TA) TAVI from 10 sites in Germany as well [20], and ROUTE enrolled patients undergoing transaortic (TAo) TAVI from 18 sites across Europe [18]. Edwards SAPIEN 3 [18-20] or XT [18] transcatheter prosthetic heart valves were used in all studies. Patients were aged $\geq 18$ years and had an indication for TAVI as evaluated by the center-specific heart team. Decisions about whether or not to perform BAV pre-dilation were made at the discretion of the treating physicians and were independent of inclusion in the registry. The individual studies enrolled between 196 and 300 evaluable patients [15-17] (Schymik G, Rudolph TK, Jacobshagen C, Rothe J, Treede H, Kerber S, Frank D, Sykorova L, Okamoto M, Thoenes M, et al. Balloonexpandable transfemoral transcatheter aortic valve implantation with or without pre-dilation - findings from the EASE-IT TF multicentre registry, submitted).

All three studies assessed outcomes at the time of the procedure and after 30 days, with the primary endpoints being composite safety endpoints (using definitions based on the Valve Academic Research Consortium-2 consensus document) at 30 days [21]. EASE-IT TF and EASE-IT TA had a 6 months follow-up, while ROUTE had no 6 months, but a 1 year follow-up.

\section{Data extraction}

For the meta-analysis, data on patient and disease characteristics, procedural details and outcomes, and longer- term outcomes were extracted. Procedural details and outcomes included: device success, post-delivery balloon dilation, procedural time, fluoroscopy time, contrast agent volume, hemodynamic instability and inotropic support (both were not available for ROUTE), transvalvular pressure gradient and periprocedural complications. Longerterm outcomes included: mortality, stroke, non-fatal myocardial infarction, new-onset dialysis, acute kidney failure, permanent pacemaker implantation, life-threatening bleeding, major vascular complications, hospitalization, valve dysfunction, New York Heart Association (NYHA) class III or IV, and Canadian Cardiovascular Society Grading of Angina Pectoris class III or IV.

\section{Statistical analysis}

Pooled data were compared between the group who underwent TAVI with BAV and the group who underwent TAVI without BAV. Unadjusted and adjusted pooled odds ratios (with 95\% confidence intervals) were calculated for procedural outcomes and longer-term outcomes. Components of the composite safety endpoints used in the original studies were analyzed individually in the metaanalysis. Procedural and 30-day outcomes were also presented according to the access route used (TF, TA or TAo) with odds ratios (and 95\% CI) for patients who did or did not undergo BAV. All statistical analyses were carried out using $\mathrm{R}$ version 3.4.3 (2017-11-30) [22], with a $p$-value of $<0.05$ considered significant.

\section{Results}

The pooled analysis population $(n=694)$ comprised 339 patients who underwent TAVI with BAV (including 56 TF, 61 TA and 222 TAo) and 355 who underwent TAVI without BAV (including 140 TF, 137 TA and 78 TAo).

\section{Baseline patient details}

Baseline patient characteristics are summarized in Table 1. Those in the no-BAV group had a higher median bodyweight (75 versus $72 \mathrm{~kg}, p=0.027$ ) and body surface area (1.84 versus $1.81 \mathrm{~cm}^{2}, p=0.032$ ) than those in the BAV group. A large proportion of patients in both groups had coronary artery disease and/or had undergone a prior cardiovascular intervention. Patients in the no-BAV group were less likely to have peripheral artery disease (23.9\% versus $43.4 \%, p=0.001$ ) and more likely to have had a prior cardiovascular intervention $(44.8 \%$ versus $36.3 \%, p=$ $0.025)$ compared with the BAV group, and had a higher median EuroSCORE II score (5 versus $4, p=0.005$ ). Aortic valve disease characteristics were similar in both groups.

\section{Periprocedural details}

The most commonly used valve size in both groups was $26 \mathrm{~mm}$ (Table 2). Post-delivery balloon dilation was required less often in the no-BAV group than in the BAV 
Table 1 Baseline patient and disease characteristics

\begin{tabular}{|c|c|c|c|c|}
\hline & $N$ & $\begin{array}{l}\text { TAVI with BAV } \\
N=339\end{array}$ & $\begin{array}{l}\text { TAVI without BAV } \\
N=355\end{array}$ & $P$-value \\
\hline \multicolumn{5}{|l|}{ Patient characteristics } \\
\hline Age (years) & 694 & $82(79-86)$ & $81(78-86)$ & 0.057 \\
\hline Female (\%) & 694 & 49.9 & 45.4 & 0.254 \\
\hline Height (cm) & 694 & $166(160-172)$ & $168(160-175)$ & 0.052 \\
\hline Weight (kg) & 694 & $72(63-82)$ & $75(63-87)$ & 0.027 \\
\hline Body surface area $\left(\mathrm{cm}^{2}\right)^{a}$ & 694 & $1.81(1.68-1.94)$ & $1.84(1.68-2.01)$ & 0.032 \\
\hline $\mathrm{BMI}\left(\mathrm{kg} / \mathrm{m}^{2}\right)$ & 692 & $26(23-29)$ & $26(24-30)$ & 0.207 \\
\hline Hypertension (\%) & 678 & 85.2 & 88.4 & 0.255 \\
\hline Diabetes (\%) & 676 & 31.0 & 32.9 & 0.621 \\
\hline Stroke, TIA (\%) & 678 & 13.5 & 16 & 0.387 \\
\hline Peripheral artery disease (\%) & 679 & 43.4 & 23.9 & $<0.001$ \\
\hline Pulmonary hypertension (\%) & 527 & 33.0 & 38.6 & 0.202 \\
\hline Creatinine > 2 mg/dL (\%) & 694 & 5.9 & 6.2 & 0.875 \\
\hline Dialysis (\%) & 361 & 6.4 & 2.7 & 0.108 \\
\hline Coronary artery disease (\%) & 694 & 61.9 & 64.8 & 0.478 \\
\hline Prior myocardial infarction (\%) & 557 & 29.8 & 24.4 & 0.182 \\
\hline Prior CV intervention (\%) & 694 & 36.3 & 44.8 & 0.025 \\
\hline Prior pacemaker / ICD implant (\%) & 501 & 17.6 & 12.7 & 0.152 \\
\hline EuroSCORE II & 588 & $4(2-8)$ & $5(3-10)$ & 0.005 \\
\hline STS Risk Score & 616 & $5.3(3.2-10.0)$ & $4.6(3.0-8.0)$ & 0.002 \\
\hline \multicolumn{5}{|l|}{ Disease characteristics } \\
\hline Echo AV peak PG (mmHg) & 533 & $70(57-82)$ & $69(55-81)$ & 0.275 \\
\hline Echo AV mean PG (mmHg) & 649 & $43(35-54)$ & $41(33-50)$ & 0.111 \\
\hline Echo $V_{\max }(\mathrm{m} / \mathrm{s})$ & 435 & $4.0(3.7-4.4)$ & $4.1(3.6-4.5)$ & 0.965 \\
\hline Echo ejection fraction (\%) & 653 & $55(47-60)$ & $55(45-60)$ & 0.324 \\
\hline Effective orifice area & 534 & $0.70(0.57-0.80)$ & $0.70(0.60-0.80)$ & 0.043 \\
\hline Indexed effective orifice area ${ }^{b}$ & 533 & $0.38(0.31-0.46)$ & $0.39(0.32-0.46)$ & 0.348 \\
\hline NYHA Class III or IV & 685 & 79.8 & 75.9 & 0.232 \\
\hline CCS grading of angina pectoris Class III or IV & 645 & 16.8 & 17.0 & 1.000 \\
\hline Dizziness or syncope & 694 & 30.1 & 30.1 & 1.000 \\
\hline
\end{tabular}

Values are median (interquartile range) unless indicated otherwise

AV Aortic valve, BAV Balloon aortic valvuloplasty, BMI Body mass index, CCS Canadian cardiovascular society, CV Cardiovascular, EuroSCORE European system for cardiac operative risk evaluation, ICD Implantable cardioverter defibrillator, NYHA New York Heart Association, PG Pressure gradient, STS Society of thoracic surgeons, TAVI Transcatheter aortic valve implantation, TIA Transient ischemic attack, $V_{\max }$ Maximum velocity

${ }^{\mathrm{a}} \mathrm{BSA}\left[\mathrm{cm} \mathrm{x} \mathrm{kg]}=0.007184 \times\right.$ height $[\mathrm{cm}]^{0.725} \times$ weight $[\mathrm{kg}]^{0.425}$ (DuBois, 1916)

${ }^{\mathrm{b}}$ iEOA Effective orifice area/body surface area

group (15.5\% versus $22.4 \%, p=0.02)$. Although the unadjusted odds ratio supported a reduced risk in the noBAV group (OR 0.63, 95\% CI 0.43-0.93), this was no longer significant in the adjusted analysis (aOR 0.67, 95\% CI 0.41-1.06) (Table 3). Median total procedural time was significantly shorter in the no-BAV group compared with the BAV group (73 versus $93 \mathrm{~min}, p<0.001$; Fig. 1), as was the median fluoroscopy time (7 versus 11 min, $p<0.001$; Fig. 1), and fewer patients in the no-BAV group received catecholamines $(9.0 \%$ versus $17.9 \%, p=$ 0.016; aOR 0.56; 95\% CI 0.24-1.38) (Tables 2 and 3).

\section{Procedural efficacy}

The device success rate was high and did not differ significantly between groups (Table 2). The rate of device malfunctions was $0.3 \%$ in the no-BAV group versus $0.6 \%$ in the BAV groups $(p=0.616)$, although the adjusted odds ratio of 0.02 (95\% CI 0.01-0.74) suggested the risk was reduced in the no-BAV group. Mean pressure gradients decreased from 41 to $9 \mathrm{mmHg}$ in the no-BAV group and from 43 to $9 \mathrm{mmHg}$ in the BAV group. Among procedural complications, atrioventricular block was significantly less common in the no-BAV group than the BAV group $(1.4 \%$ 
Table 2 Procedural data and outcomes

\begin{tabular}{|c|c|c|c|c|c|}
\hline & \multicolumn{2}{|c|}{ TAVI with BAV } & \multicolumn{2}{|c|}{ TAVI without BAV } & \multirow[t]{2}{*}{$P$-value } \\
\hline & $\mathrm{N}$ & Value & $\mathrm{N}$ & Value & \\
\hline Valve size & 339 & & 355 & & $<0.001$ \\
\hline $20-23 \mathrm{~mm}$ & & 28.9 & & 31.0 & \\
\hline $26 \mathrm{~mm}$ & & 45.1 & & 41.1 & \\
\hline $29 \mathrm{~mm}$ & & 26.0 & & 27.9 & \\
\hline Post-delivery balloon dilation (\%) & 339 & 22.4 & 355 & 15.5 & 0.020 \\
\hline Quantity contrast agent used (mL) & 303 & $100(73-131)$ & 349 & $95(70-126)$ & 0.343 \\
\hline Access complications (\%) & 339 & 0.9 & 355 & 2.3 & 0.224 \\
\hline Hemodynamic instability (\%) & 117 & 5.1 & 277 & 2.5 & 0.219 \\
\hline Catecholamine use (inotropes) (\%) & 117 & 17.9 & 277 & 9.0 & 0.016 \\
\hline Effective orifice area post-surgery & 119 & $1.89(1.59 / 2.30)$ & 114 & $1.80(1.50 / 2.20)$ & 0.378 \\
\hline Indexed effective orifice area & 282 & $0.38(0.31 / 0.46)$ & 251 & $0.39(0.31 / 0.46)$ & 0.348 \\
\hline AV mean PG post-surgery & 286 & $9.0(6.0 / 12.0)$ & 252 & $9.0(6.0 / 12.8)$ & 0.862 \\
\hline Paravalvular regurgitation & 339 & & 351 & & $<0.001$ \\
\hline None/trace & & 78.5 & & 84.3 & \\
\hline Mild & & 18.9 & & 15.1 & \\
\hline Moderate & & 2.4 & & 0.6 & \\
\hline Severe & & 0.3 & & 0.0 & \\
\hline Device success (\%) & 339 & 97.9 & 355 & 99.2 & 0.214 \\
\hline Second valve needed (\%) & 339 & 1.2 & 355 & 0.8 & 0.719 \\
\hline Conversion to surgery (\%) & 141 & 3.5 & 280 & 2.1 & 0.518 \\
\hline Coronary artery obstruction requiring intervention (\%) & 213 & 0.9 & 71 & 0.0 & 1.000 \\
\hline Device malfunction (\%) & 339 & 0.6 & 355 & 0.3 & 0.616 \\
\hline Atrioventricular block (\%) & 339 & 4.1 & 355 & 1.4 & 0.035 \\
\hline Aortic root rupture (\%) & 339 & 0.3 & 355 & 0.0 & 0.488 \\
\hline Correct positioning of a single prosthetic valve into the proper anatomical location & 339 & 99.1 & 355 & 99.7 & 0.363 \\
\hline Intended performance of the prosthetic valve & 287 & 97.9 & 217 & 98.6 & 0.738 \\
\hline
\end{tabular}

Values are median (interquartile range) unless indicated otherwise

AV Aortic valve, BAV Balloon aortic valvuloplasty, CI Confidence interval, OR Odds ratio, PG Pressure gradient, TAVI Transcatheter aortic valve implantation

versus $4.1 \%, p=0.035$ ); however, although the unadjusted odds ratio supported a reduced risk in the no-BAV group (OR 0.33, 95\% CI 0.11-0.88), this was no longer significant in the adjusted analysis (aOR $0.44,95 \%$ CI $0.12-1.38$ ) (Table 3). Most patients had no paravalvular leakage after the procedure (no-BAV 84.3\%; BAV 78.5\%); moderate/ severe paravalvular regurgitation was less common in the no-BAV group than the BAV group $(p=0.001$; Table 2). There were no significant differences between groups for other procedural complications.

\section{0-day outcomes}

There were no significant between-group differences in the rate of death (Fig. 2), stroke, permanent pacemaker

Table 3 Procedural data and outcomes

\begin{tabular}{lllll}
\hline & TAVI with BAV & TAVI without BAV & OR (95\% Cl) & Adjusted OR $(95 \%$ Cl) \\
\hline Post-delivery balloon dilation (\%) & 22.4 & 15.5 & $0.63(0.43-0.93)$ & $0.67(0.41-1.06)$ \\
Catecholamine use (Use of inotropes) (\%) & 17.9 & 9.0 & $0.45(0.24-0.85)$ & $0.56(0.24-1.38)$ \\
Atrioventricular block (\%) & 4.1 & 1.4 & $0.33(0.11-0.88)$ & $0.44(0.12-1.38)$ \\
$\begin{array}{l}\text { Correct positioning of a single prosthetic valve } \\
\text { into the proper location (\%) }\end{array}$ & 99.1 & 99.7 & $3.16(0.4-64.07)$ & $2.13(0.24-45.99)$ \\
Intended performance of the prosthetic valve (\%) & 97.9 & 98.6 & $2.11(0.55-10.08)$ & $1.06(0.22-5.69)$ \\
\hline
\end{tabular}




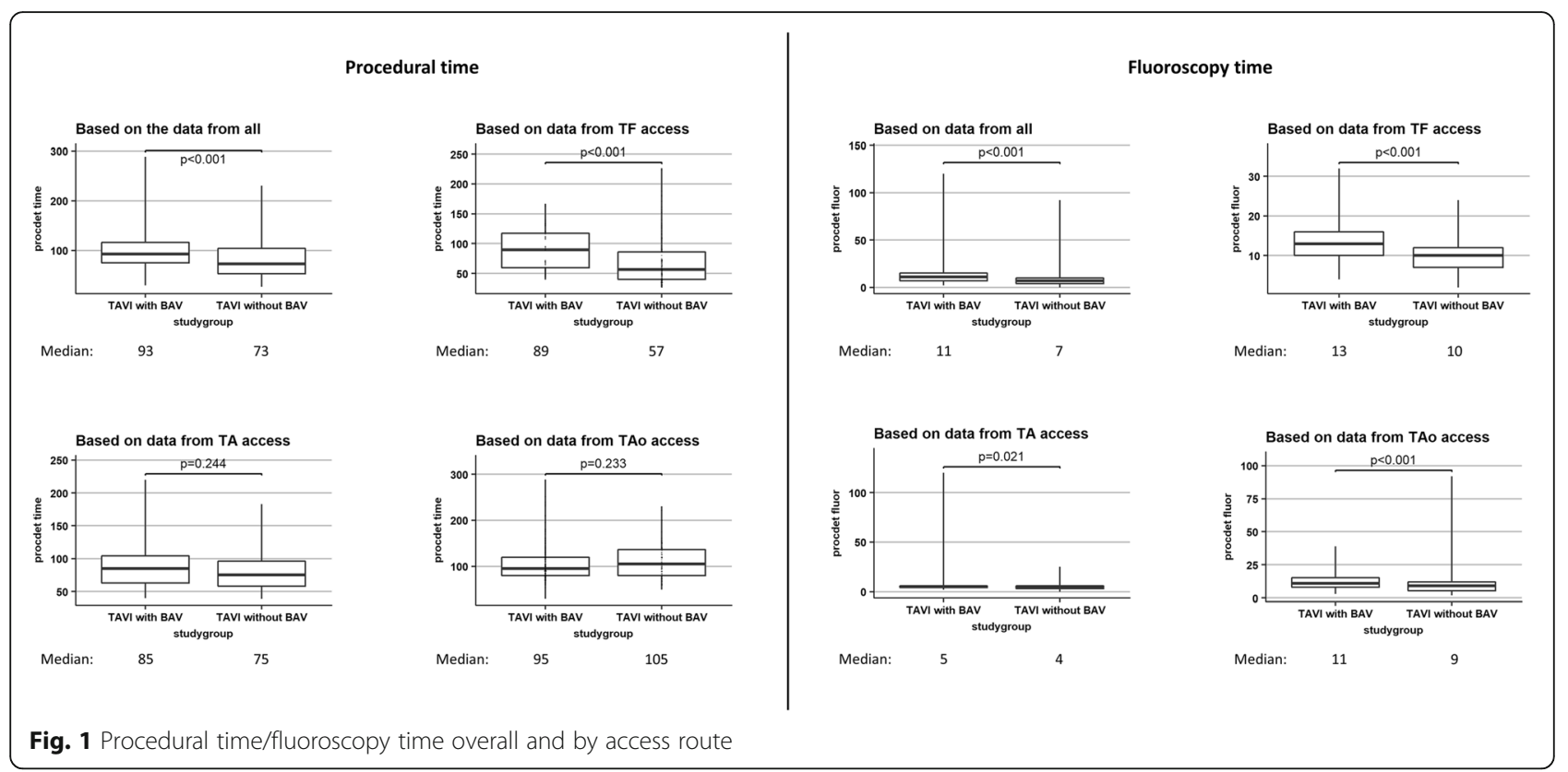

implantation or other outcomes at day 30 (Table 4), with the exception of patients in the no-BAV group being less likely in NYHA class III/IV than those in the BAV group (17.6\% versus $54.5 \%$; aOR $0.18,95 \%$ CI $0.12-0.27$ ).

\section{Outcomes by access route}

Outcomes for patients receiving TAVI with or without BAV according to the access route are summarized in Table 5 (procedural outcomes) and Table 6 (30-day outcomes). The need for post-delivery balloon dilation was reduced in the no-BAV group compared with the BAV group among TF-TAVI patients (OR 0.43, 95\% CI 0.210.89 ) but not TA-TAVI or TAo-TAVI patients (Table 5). Total procedure time was reduced in the no-BAV group compared with the BAV only among TF-TAVI patients (56.5 versus $89.5 \mathrm{~min}, p<0.001$ ) and not among TA-TAVI or TAo-TAVI patients (Fig. 1), whereas fluoroscopy time was reduced in the no-BAV group for all access routes (Fig. 1). The quantity of contrast agent used was reduced in the no-BAV group only among patients undergoing TAo-TAVI ( 80 versus $94 \mathrm{~mL}, p=0.008$ ). Use of inotropes was reduced in the no-BAV group only among patients undergoing TA-TAVI (17.5\% versus $32.8 \%$; OR 0.44, 95\% CI 0.22-0.87). Most patients had no paravalvular regurgitation after TAVI irrespective of the use of BAV and route of access (76.6-86.0\%). Moderate/severe paravalvular regurgitation appeared to be more common in the BAV group than the no-BAV group among those who underwent TAo-TAVI (Table 5).

No significant differences in 30-day outcomes between the no-BAV and BAV groups were seen in the analysis by route of access (Table 6) except for a reduced likelihood of being in NYHA Class III/IV in the no-BAV group treated with TAo-TAVI $(60.3 \%$ versus $80.6 \%$; OR 0.36 , 95\% CI $0.21-0.64$ ).

\section{Discussion}

This meta-analysis of three prospective multicenter registry studies confirmed that omission of the BAV predilation step prior to TAVI using the balloon-expandable Edwards SAPIEN 3 (or XT) transcatheter heart valve had no adverse effect on procedural or 30-day and 6 months outcomes. On the contrary, it was associated with shorter procedure times and less PVL. The results suggest that BAV is unnecessary in the majority of patients undergoing TF-TAVI, TA-TAVI or TAo-TAVI.

\section{Patient and disease characteristics}

Patients in the BAV group were more likely to have peripheral artery disease whereas those in the no-BAV group were more likely to have undergone previous cardiovascular interventions and had a higher EUROSCORE II score. Specific aortic valve-related disease characteristics were generally similar between the groups. The reasons that clinicians selected conventional or direct TAVI were not evaluated in the meta-analysis. One of the individual studies reported that common reasons for omitting BAV were a desire to reduce procedural duration and a perceived risk of cerebral microemboli. Common reasons for performing BAV included to facilitate crossing the native aortic valve and doubts about the choice of valve size [17] (Schymik G, Rudolph TK, Jacobshagen C, Rothe J, Treede H, Kerber S, Frank D, Sykorova L, Okamoto M, Thoenes M, et al. Balloon-expandable transfemoral transcatheter aortic valve implantation with or without pre-dilation - findings from the EASE-IT TF multicentre registry, submitted). 


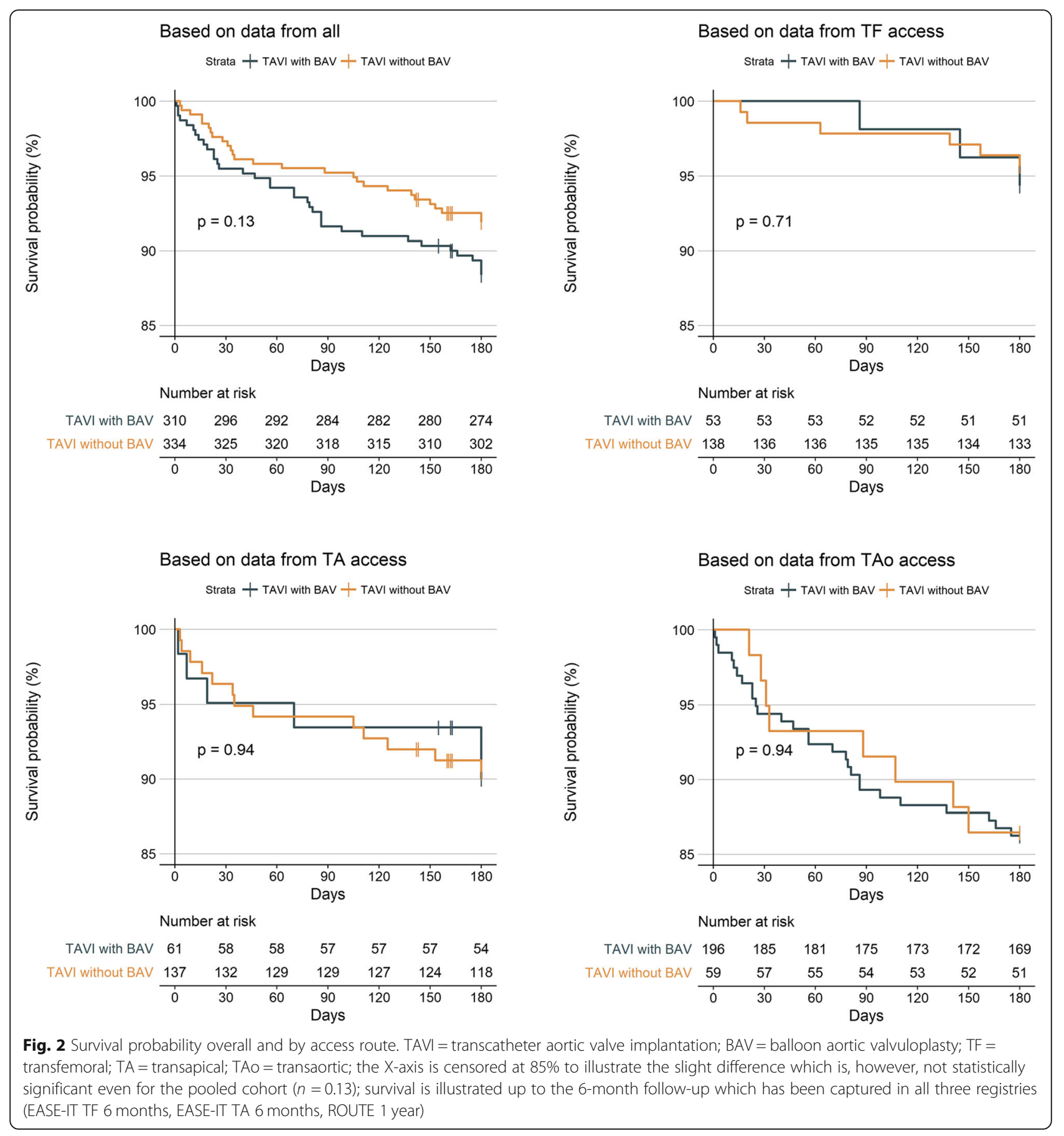

\section{Periprocedural data}

As would be expected, omitting the BAV step led to a significantly shorter total procedural time (by approximately 20 min compared with the procedure including BAV). Fluoroscopy time was also shorter in the no-BAV group (by $5 \mathrm{~min}$ ), although the quantity of contrast agent used was not reduced significantly. A previous meta-analysis of clinical studies also found that procedural time was reduced by approximately $20 \mathrm{~min}$ with the omission of BAV; that analysis found no difference in fluoroscopy time but did report reduced use of contrast medium [12].

It might be expected that there would be a potentially greater need for post-procedural dilation in the group that did not undergo pre-dilation, as seen in one previous registry study where the rate was $26 \%$ in the noBAV group compared with $6 \%$ in the BAV group [10]. However, in the current meta-analysis post-delivery balloon dilation was less common in the no-BAV group 
Table 4 Outcomes at 30 days

\begin{tabular}{|c|c|c|c|c|c|c|}
\hline & \multicolumn{2}{|c|}{ TAVI with BAV } & \multicolumn{2}{|c|}{ TAVI without BAV } & \multicolumn{2}{|l|}{ OR $(95 \% \mathrm{Cl})$} \\
\hline & $\bar{N}$ & $\%$ & $\bar{N}$ & $\%$ & Not-adjusted & Adjusted $^{a}$ \\
\hline Death (\%) & 327 & 1.8 & 343 & 1.5 & $0.79(0.23-2.65)$ & $0.4(0.06-1.86)$ \\
\hline Stroke (\%) & 327 & 0.9 & 341 & 0.3 & $0.32(0.02-2.5)$ & $0.79(0.02-27.7)$ \\
\hline Non-fatal MI (\%) & 336 & 0.6 & 349 & 0.9 & $1.45(0.24-11.05)$ & $1.29(0.12-13.1)$ \\
\hline New-onset dialysis (\%) & 332 & 3.9 & 348 & 3.7 & $0.95(0.43-2.1)$ & $0.97(0.4-2.32)$ \\
\hline Creatinine increase (\%) & 268 & 1.5 & 210 & 1.4 & $0.96(0.19-4.38)$ & $0.42(0.02-3.22)$ \\
\hline Permanent pacemaker implantation (\%) & 337 & 10.1 & 350 & 8.6 & $0.84(0.5-1.4)$ & $1.17(0.62-2.2)$ \\
\hline Life-threatening bleeding (\%) & 333 & 3.0 & 345 & 1.4 & $0.48(0.15-1.35)$ & $0.42(0.09-1.48)$ \\
\hline Major vascular complications (\%) & 333 & 4.5 & 345 & 3.5 & $0.76(0.35-1.66)$ & $0.63(0.21-1.65)$ \\
\hline Hospitalization (\%) & 333 & 2.7 & 344 & 1.2 & $0.42(0.11-1.31)$ & $0.48(0.09-1.9)$ \\
\hline Valve dysfunction (\%) & 322 & 0.9 & 337 & 0.0 & - & - \\
\hline NYHA Class III or IV (\%) & 336 & 54.5 & 346 & 17.6 & $0.18(0.13-0.25)$ & $0.18(0.12-0.27)$ \\
\hline CCS grading of angina pectoris Class III or IV (\%) & 308 & 1.6 & 296 & 1.0 & $0.62(0.13-2.55)$ & $0.98(0.18-4.8)$ \\
\hline
\end{tabular}

BAV Balloon aortic valvuloplasty, Cl Confidence interval, CCS Canadian cardiovascular society, MI Myocardial infarction, NYHA New York Heart Association, OR Odds ratio, TAVI Transcatheter aortic valve implantation

${ }^{a}$ data were adjusted for age, gender, prior MI, stroke / TIA, creatinine, ejection fraction and NYHA class

than in the BAV group, driven largely by TF-TAVI patients. Other meta-analyses of clinical studies found no significant difference in post-procedural dilation between BAV and non-BAV groups $[11,12]$.

The rate of device success in the current meta-analysis was high regardless of whether or not BAV was performed, and did not differ significantly between the groups, which is consistent with other registry studies $[9,14]$ and metaanalyses of clinical studies [11, 12]. However, the adjusted analysis in the current meta-analysis suggested that omission of BAV was associated with a reduced risk of device malfunction. Overall, these results suggest that decisions not to perform BAV were appropriate for patients actually selected for this approach. Of note, the percentage of TAVR procedures without BAV increased over time in the three analyzed studies which might be mainly attributed to the increasing experience of operators and growing evidence that omitting BAV is not disadvantageous in the overall TAVR procedure.

\section{Periprocedural complications}

Patients undergoing TAVI and/or BAV can develop arrhythmias, coronary obstruction or severe aortic regurgitation which may necessitate the use of catecholamines. In the current meta-analysis, the need for catecholamine use was reduced when BAV was omitted. In addition, the risk of atrioventricular block was lower when BAV was omitted, although this relationship was no longer significant when the analysis was fully adjusted. Moderate/severe paravalvular regurgitation after TAVI was uncommon in either group, but it appeared to be more common in the BAV group than the no-BAV group among those who underwent TAo-TAVI.

\section{Early safety/efficacy}

The current meta-analysis found no significant differences between the BAV and no-BAV groups in terms of the risk of mortality, stroke, permanent pacemaker implantation or other clinical outcomes at 30 days after TAVI, with one exception. TAVI without BAV was associated with a reduced risk of the patient being in NYHA class III/IV at day 30, which remained significant in the adjusted analysis. The proportion of patients in NYHA class III/IV at baseline did not differ between the groups. The reason for this finding is not clear, but it may relate to the fact that in the initially conducted studies (ROUTE and EASE-it TA) patients were mainly treated with BAV whereas in the latter trial (EASE-it TF) the majority of patients underwent TAVR without BAV. When analyzing these studies together the access route might be the main driver for worse outcome regarding NYHA class, since non-TF treated patients would be expected to undergo a longer recovery period. Other metaanalyses of clinical studies have not reported differences in NYHA class at day $30[11,12]$.

\section{Limitations}

The non-randomized nature of the registry studies makes them susceptible to bias. The decision about whether or not to perform BAV was made by the treating clinician and may have been determined by the severity of illness, complexity of the valve anatomy and their perception of the likelihood of successful implantation; thus, it is possible that BAV might have been selected for more complex cases. The procedures being evaluated are subject to a learning curve and less 
Table 5 Procedural outcomes by access route

\begin{tabular}{|c|c|c|c|c|c|c|}
\hline & \multicolumn{2}{|l|}{ TF access } & \multicolumn{2}{|l|}{ TA access } & \multicolumn{2}{|c|}{ TAo access } \\
\hline & $X_{w} / X_{w o}$ & $p$-value & $x_{w} / X_{w o}$ & $p$-value & $X_{w} / X_{\text {wo }}$ & $p$-value \\
\hline Valve size & & 0.038 & & 0.005 & & 0.001 \\
\hline $20-23 \mathrm{~mm}$ & $\begin{array}{l}37.5 / \\
31.4\end{array}$ & & $\begin{array}{l}29.5 / \\
30.7\end{array}$ & & $\begin{array}{l}26.6 / \\
30.8\end{array}$ & \\
\hline $26 \mathrm{~mm}$ & $\begin{array}{l}23.2 / \\
39.3\end{array}$ & & $\begin{array}{l}49.2 / \\
40.9\end{array}$ & & $\begin{array}{l}49.5 / \\
44.9\end{array}$ & \\
\hline $29 \mathrm{~mm}$ & $\begin{array}{l}39.3 / \\
29.3\end{array}$ & & $\begin{array}{l}21.3 / \\
28.5\end{array}$ & & $\begin{array}{l}23.9 / \\
24.4\end{array}$ & \\
\hline Quantity contrast agent used (mL) & $\begin{array}{l}131 / \\
120\end{array}$ & 0.240 & $85 / 80$ & 0.681 & $94 / 80$ & 0.008 \\
\hline Effective orifice area post-surgery & $\begin{array}{l}1.40 / \\
1.65\end{array}$ & 0.203 & $\begin{array}{l}2.10 / \\
2.00\end{array}$ & 0.222 & $\begin{array}{l}1.80 / \\
1.82\end{array}$ & 0.809 \\
\hline Indexed effective orifice area & $\begin{array}{l}0.71 / \\
0.87\end{array}$ & 0.175 & $\begin{array}{l}1.17 / \\
1.04\end{array}$ & 0.137 & $\begin{array}{l}1.04 / \\
1.00\end{array}$ & 0.857 \\
\hline AV mean PG post-surgery & $12 / 11$ & 0.138 & $4 / 5$ & 0.641 & $9 / 10$ & 0.863 \\
\hline Paravalvular regurgitation & & 0.001 & & $<0.001$ & & $<0.001$ \\
\hline None/trace & $\begin{array}{l}85.7 / \\
86.0\end{array}$ & & $\begin{array}{l}78.7 / \\
84.7\end{array}$ & & $\begin{array}{l}76.6 / \\
80.8\end{array}$ & \\
\hline Mild & $\begin{array}{l}14.3 / \\
13.2\end{array}$ & & $\begin{array}{l}21.3 / \\
14.6\end{array}$ & & $\begin{array}{l}19.4 / \\
19.2\end{array}$ & \\
\hline Moderate & $0 / 0.7$ & & $0 / 0.7$ & & $3.6 / 0$ & \\
\hline \multirow[t]{3}{*}{ Severe } & $0 / 0$ & & $0 / 0$ & & $0.5 / 0$ & \\
\hline & \multicolumn{2}{|l|}{ TF access } & \multicolumn{2}{|l|}{ TA access } & \multicolumn{2}{|c|}{ TAo access } \\
\hline & $X_{w} / X_{\text {wo }}$ & OR $(95 \% \mathrm{Cl})$ & $X_{w} / X_{w o}$ & OR $(95 \% \mathrm{Cl})$ & $X_{w} / X_{w o}$ & OR $(95 \% \mathrm{Cl})$ \\
\hline Post-delivery balloon dilation (\%) & $\begin{array}{l}30.4 / \\
15.7\end{array}$ & $\begin{array}{l}0.43(0.21- \\
0.89)\end{array}$ & $\begin{array}{l}14.8 / \\
9.5\end{array}$ & $\begin{array}{l}1.65(0.65- \\
4.07)\end{array}$ & $\begin{array}{l}22.5 / \\
25.6\end{array}$ & $\begin{array}{l}0.84(0.47- \\
1.56)\end{array}$ \\
\hline Access complications (\%) & $0 / 5$ & n.a. & $0 / 0.7$ & n.a. & $1.4 / 0$ & n.a. \\
\hline Hemodynamic instability (\%) & $3.6 / 0.7$ & $\begin{array}{l}0.19(0.01- \\
2.07)\end{array}$ & $6.6 / 4.4$ & $\begin{array}{l}0.65(0.18- \\
2.63)\end{array}$ & n.c. & n.a. \\
\hline Catecholamine use (\%) & $1.8 / 0.7$ & $\begin{array}{l}0.4(0.02- \\
10.12)\end{array}$ & $\begin{array}{l}32.8 / \\
17.5\end{array}$ & $\begin{array}{l}0.44(0.22- \\
0.87)\end{array}$ & n.c. & n.a. \\
\hline Device success (\%) & $\begin{array}{l}92.9 / \\
98.6\end{array}$ & $\begin{array}{l}5.31(1.01- \\
39.12)\end{array}$ & $\begin{array}{l}100 / \\
100\end{array}$ & n.a. & $\begin{array}{l}98.6 / \\
98.7\end{array}$ & $\begin{array}{l}0.95(0.05- \\
7.53)\end{array}$ \\
\hline Second valve needed (\%) & $0 / 0.7$ & n.a. & $0 / 0$ & n.a. & $1.8 / 2.6$ & $0.7(0.13-5.1)$ \\
\hline Conversion to surgery (\%) & $0 / 2.9$ & n.a. & $0 / 1.5$ & n.a. & $1.7 / 0$ & n.a. \\
\hline Device malfunction (\%) & $0 / 0$ & n.a. & $0 / 0.7$ & n.a. & $0.9 / 0$ & n.a. \\
\hline Atrioventricular block (\%) & $3.6 / 2.1$ & $\begin{array}{l}0.59(0.1- \\
4.58)\end{array}$ & $1.6 / 1.5$ & $\begin{array}{l}0.89(0.08- \\
19.34)\end{array}$ & $5 / 0$ & n.a. \\
\hline Aortic root rupture (\%) & $0 / 0$ & n.a. & $0 / 0$ & n.a. & $0.5 / 0.0$ & n.a. \\
\hline $\begin{array}{l}\text { Correct positioning of a single prosthetic valve into the proper } \\
\text { anatomical location (\%) }\end{array}$ & $\begin{array}{l}100 / \\
100\end{array}$ & n.a. & $\begin{array}{l}100 / \\
100\end{array}$ & n.a. & $\begin{array}{l}98.6 / \\
98.7\end{array}$ & $\begin{array}{l}1.05(0.13- \\
21.5)\end{array}$ \\
\hline Intended performance of the prosthetic valve (\%) & $\begin{array}{l}92.9 / \\
98.6\end{array}$ & $\begin{array}{l}5.31(1.01- \\
39.1)\end{array}$ & $\begin{array}{l}100 / \\
100\end{array}$ & n.a. & $\begin{array}{l}99.1 / \\
98.7\end{array}$ & $\begin{array}{l}0.7(0.07- \\
15.2)\end{array}$ \\
\hline
\end{tabular}

Values are median (interquartile range) unless indicated otherwise

AV Aortic valve, CI Confidence interval, n.a. Not applicable (e.g. no ratio), n.c. Data not collected, OR Odds ratio, PG Pressure gradient, TA Transapical, TAo Transaortic, TF Transfemoral, $X_{w}$ Transcatheter aortic valve implantation with balloon aortic valvuloplasty, $X_{w o}=$ TAVI Transcatheter aortic valve implantation without balloon aortic valvuloplasty

experienced surgeons/teams might have been more likely to perform BAV. However, the meta-analysis was adjusted for potential confounders where possible. All three studies evaluated balloon-expandable Edwards
SAPIEN valves (primarily the SAPIEN 3), which reduced confounding associated with the use of different devices; however, the results therefore do not necessarily apply to TAVI performed using other transcatheter valve 
Table 6 Outcomes at 30 days by access route

\begin{tabular}{|c|c|c|c|c|c|c|}
\hline & TF access & & TA access & & TAo access & \\
\hline & $X_{w} / X_{w o}$ & OR $(95 \% \mathrm{Cl})$ & $X_{w} / X_{w o}$ & OR $(95 \% \mathrm{Cl})$ & $X_{w} / X_{w o}$ & OR $(95 \% \mathrm{Cl})$ \\
\hline Death (\%) & $0 / 1.4$ & n.a. & $0 / 0.8$ & n.a. & $2.8 / 2.8$ & $1(0.14-4.46)$ \\
\hline Stroke (\%) & $0 / 0$ & n.a. & $0 / 0$ & n.a. & $1.4 / 1.4$ & $1(0.05-7.95)$ \\
\hline Non-fatal MI (\%) & $0 / 0.7$ & n.a. & $1.6 / 0.7$ & $0.44(0.05-11.28)$ & $0.5 / 1.4$ & $2.99(0.12-76.16)$ \\
\hline New onset dialysis (\%) & $0 / 0.7$ & n.a. & $4.9 / 5.1$ & $1.04(0.25-4.96)$ & $9.2 / 10.3$ & $1.13(0.23-4.66)$ \\
\hline Creatinine increase (\%) & $0 / 1.4$ & n.a. & & - & $1.9 / 1.4$ & $0.74(0.04-5.13)$ \\
\hline PPI (\%) & $8.9 / 7.2$ & $0.79(0.27-2.64)$ & $14.8 / 10.2$ & $0.66(0.27-1.67)$ & $9.1 / 8.1$ & $0.88(0.31-2.17)$ \\
\hline Life-threatening bleeding (\%) & $1.8 / 1.4$ & n.a. & $1.7 / 0.8$ & $0.44(0.02-11.13)$ & $3.7 / 2.7$ & $0.73(0.11-3.01)$ \\
\hline Major vascular complications (\%) & $10.7 / 5.8$ & $0.51(0.17-1.61)$ & $1.7 / 1.5$ & $0.88(0.08-19.09)$ & $3.7 / 2.7$ & $0.73(0.11-3.01)$ \\
\hline Hospitalization (\%) & $1.8 / 0.7$ & $0.40(0.02-10.27)$ & $1.7 / 0$ & n.a. & $3.2 / 4.1$ & $1.28(0.27-4.74)$ \\
\hline Valve dysfunction (\%) & $0 / 0$ & n.a. & $0 / 0$ & n.a. & $1.4 / 0$ & n.a. \\
\hline NYHA Class III or IV (\%) & $5.04 / 8.1$ & $1.55(0.46-7.08)$ & $1.7 / 2.3$ & $1.33(0.17-27.11)$ & $80.6 / 60.3$ & $0.36(0.21-0.64)$ \\
\hline CCS III or IV (\%) & $0 / 0$ & n.a. & $0 / 0$ & n.a. & $2.5 / 6.4$ & $2.62(0.52-11.08)$ \\
\hline
\end{tabular}

Values are median (interquartile range) unless indicated otherwise

BAV Balloon aortic valvuloplasty, CCS Canadian cardiovascular society, MI Myocardial infarction, NYHA New York Heart Association, n.a. Not applicable, PPI Permanent pacemaker implantation, TA Transapical, TAo Transaortic, TF Transfemoral, $X_{w}$ Transcatheter aortic valve implantation with balloon aortic valvuloplasty, $X_{\text {wo }}=$ TAVI Transcatheter aortic valve implantation without balloon aortic valvuloplasty

systems. When analyzed by route of access, there were too few 30-day outcome events to allow a meaningful interpretation.

\section{Conclusions}

This meta-analysis of real-world data indicates that TAVI performed without BAV is advantageous as it has a high device success rate, reduced procedure and fluoroscopy time, reduced risk of PVL and no adverse effect on short-term clinical outcomes.

\section{Abbreviations}

aOR: Adjusted odds ratio; BAV: Balloon aortic valvuloplasty; OR: Odds ratio; PV: ParaValvular; TA: TransApical; TAo: TransAortic; TAVI: Transcatheter aortic valve implantation; TF: TransFemoral

\section{Acknowledgements}

Data were captured using the s4trials Software provided by Software for Trials Europe $\mathrm{GmbH}$, Berlin, Germany.

\section{Authors' contributions}

JOA, NB, MK, GS, CB, MR, VB, JS, HS, AB, CD, PB, JK, MT, SB and TR were involved in the conception and design of the analysis. NB, MK, MR and VB (ROUTE), JS and HS (EASE-IT TA), SB, CB and GS (EASE-IT TF) are the principal investigators of the single registries or key centers. $A B$ and $C D$ were responsible for the statistical analysis. JOA, PB, and TR wrote the first draft of the manuscript which all authors (JOA, NB, MK, GS, CB, MR, $V B, J S, H S, A B, C D, P B, J K, M T, S B$ and $T R$ ) revised it for important intellectual content. All authors have given final approval of the version to be published.

\section{Funding}

A research grant was provided by Edwards Lifescience, Nyon, Switzerland to IPPMed. MT and JK, as representatives of the funder, contributed, as the other authors, to the overall development of the manuscript (see below). They had an equal vote during the discussion of conflicting comments but no veto right.
Availability of data and materials

Available from the corresponding author upon reasonable request.

Ethics approval and consent to participate

All three studies included in the meta-analysis were multicenter, prospective, observational registry studies conducted under the guidance of the Institute for Pharmacology and Preventive Medicine (Cloppenburg, Germany). Full details of the design and methodology for each study have been reported previously [18-20]. Ethical approval for each study and written patient informed consent was obtained.

Consent for publication

Not applicable.

\section{Competing interests}

$\mathrm{NB}, \mathrm{MR}, \mathrm{VB}, \mathrm{JS}, \mathrm{HS}, \mathrm{CS}, \mathrm{GS}, \mathrm{SB}$ and TR have received consultancy fees from different companies producing heart valves. JK and MT are employees of Edwards Lifesciences. PB is the representative of the Institute for Pharmacology and Preventive Medicine, Cloppenburg (IPPMed), Germany. $A B$ is a consultant for IPPMed. CD, JOA, and MK declare no conflicts of interest.

\section{Author details}

${ }^{1}$ Department of Cardiology, University of Cologne Heart Center, Cologne, Germany. ${ }^{2}$ Department of Cardiac Surgery, Medical University Innsbruck, Innsbruck, Austria. ${ }^{3}$ Medical Clinic IV, Department of Cardiology, Municipal Hospital, Karlsruhe, Germany. ${ }^{4}$ Department of Cardiology, Immanuel Clinic Bernau, Heart Center Brandenburg, Bernau, Germany. ${ }^{5}$ Institut Hospitalier Jacques Cartier, Massy, France. ${ }^{6}$ Columbia University Medical Center / New York-Presbyterian Hospital, New York, NY, USA. ${ }^{7}$ Clinic for Cardiosurgery and Thoracic Surgery, Berufsgenossenschaftliches Universitätsklinikum Bergmannsheil, Bochum, Germany. ${ }^{8}$ Department Cardiovascular Surgery, University Heart Center Freiburg, Bad Krozingen, Germany. ${ }^{9}$ Healthtwist $\mathrm{GmbH}$, Berlin, Germany. ${ }^{10}$ Institute for Pharmacology and Preventive Medicine, Bahnhofstrasse 20, 49661 Cloppenburg, Germany. ${ }^{11}$ Edwards Lifesciences, Medical Affairs/Professional Education, Prague, Czech Republic.

${ }^{12}$ Edwards Lifesciences, Medical Affairs/Professional Education, Nyon, Switzerland. ${ }^{13}$ Department of Cardiology, Heart and Diabetes Center Bad Oeynhausen, Ruhr-University of Bochum, Bad Oeynhausen, Germany. 
Received: 3 May 2019 Accepted: 5 July 2019

Published online: 19 July 2019

\section{References}

1. Walther T, Dewey T, Borger MA, Kempfert J, Linke A, Becht R, Falk V, Schuler G, Mohr FW, Mack M. Transapical aortic valve implantation: step by step. Ann Thorac Surg. 2009:87(1):276-83.

2. Patsalis PC, Al-Rashid F, Neumann T, Plicht B, Hildebrandt HA, Wendt D, Thielmann M, Jakob HG, Heusch G, Erbel R, et al. Preparatory balloon aortic valvuloplasty during transcatheter aortic valve implantation for improved valve sizing. JACC Cardiovasc Interv. 2013:6(9):965-71.

3. Grube E, Naber C, Abizaid A, Sousa E, Mendiz O, Lemos P, Kalil Filho R Mangione J, Buellesfeld L. Feasibility of transcatheter aortic valve implantation without balloon pre-dilation: a pilot study. JACC CardiovasC Interv. 2011:4(7):751-7.

4. Vahanian A, Himbert D. Transcatheter aortic valve implantation: could it be done without prior balloon valvuloplasty? JACC Cardiovasc Interv. 2011:4(7):758-9.

5. Ben-Dor I, Pichard AD, Satler LF, Goldstein SA, Syed Al, Gaglia MA Jr, Weissman G, Maluenda G, Gonzalez MA, Wakabayashi K, et al. Complications and outcome of balloon aortic valvuloplasty in high-risk or inoperable patients. JACC Cardiovasc Interv. 2010;3(11):1150-6.

6. Erdoes G, Basciani R, Huber C, Stortecky S, Wenaweser P, Windecker S, Carrel T, Eberle B. Transcranial Doppler-detected cerebral embolic load during transcatheter aortic valve implantation. Eur J Cardiothorac Surg. 2012;41(4): 778-83 discussion 783-774

7. Gensas CS, Caixeta A, Siqueira D, Carvalho LA, Sarmento-Leite R, Mangione JA, Lemos PA, Colafranceschi AS, Caramori P, Ferreira MC, et al. Predictors of permanent pacemaker requirement after transcatheter aortic valve implantation: insights from a Brazilian registry. Int J Cardiol. 2014;175(2):248-52.

8. Drews T, Pasic M, Buz S, Unbehaun A, Dreysse S, Kukucka M, Mladenow A, Hetzer R. Transcranial Doppler sound detection of cerebral microembolism during transapical aortic valve implantation. Thorac Cardiovasc Surg. 2011; 59(4):237-42.

9. Deharo P, Jaussaud N, Grisoli D, Camus O, Resseguier N, Le Breton H, Auffret $V$, Verhoye JP, Koning R, Lefevre T, et al. Impact of direct transcatheter aortic valve replacement without balloon aortic Valvuloplasty on procedural and clinical outcomes: insights from the FRANCE TAVI registry. JACC Cardiovasc Interv. 2018;11(19):1956-65

10. Fink N, Segev A, Kornowski R, Finkelstein A, Assali A, Rozenbaum Z, VakninAssa H, Halkin A, Fefer P, Ben-Shoshan J, et al. Balloon dilatation and outcome among patients undergoing trans-femoral aortic valve replacement. Int J Cardiol. 2017;230:537-41.

11. Bagur R, Kwok CS, Nombela-Franco L, Ludman PF, de Belder MA, Sponga S, Gunning M, Nolan J, Diamantouros P, Teefy PJ, et al. Transcatheter aortic valve implantation with or without preimplantation balloon aortic valvuloplasty: a systematic review and meta-analysis. J Am Heart Assoc. 2016:5(6). https://doi.org/10.1161/JAHA.115.003191.

12. Auffret V, Regueiro A, Campelo-Parada F, Del Trigo M, Chiche O, Chamandi C, Puri R, Rodes-Cabau J. Feasibility, safety, and efficacy of transcatheter aortic valve replacement without balloon predilation: a systematic review and meta-analysis. Catheter Cardiovasc Interv. 2017:90(5):839-50.

13. Martin GP, Sperrin M, Bagur R, de Belder MA, Buchan I, Gunning M, Ludman PF, Mamas MA. Pre-implantation balloon aortic valvuloplasty and clinical outcomes following transcatheter aortic valve implantation: a propensity score analysis of the UK registry. J Am Heart Assoc. 2017;6(2). https://doi. org/10.1161/JAHA.116.004695.

14. Bernardi FL, Ribeiro HB, Carvalho LA, Sarmento-Leite R, Mangione JA, Lemos PA, Abizaid A, Grube E, Rodes-Cabau J, de Brito FS Jr. Direct transcatheter heart valve implantation versus implantation with balloon predilatation: insights from the Brazilian transcatheter aortic valve replacement registry. Circ Cardiovasc Interv. 2016;9:e003605 originally published August 5, 2016(8).

15. Strauch J, Wendt D, Diegeler A, Heimeshoff M, Hofmann S, Holzhey D, Oertel F, Wahlers T, Kurucova J, Thoenes M, et al. Balloon-expandable transapical transcatheter aortic valve implantation with or without predilation of the aortic valve: results of a multicentre registry. Eur J Cardiothorac Surg. 2018;53(4):771-7

16. Bonaros N, Kofler M, Frank D, Cocchieri R, Jagielak D, Aiello M, Lapeze J, Laine M, Chocron S, Muir D, et al. Balloon-expandable transaortic transcatheter aortic valve implantation with or without predilation. J Thorac Cardiovasc Surg. 2018;155(3):915-23.
17. Butter C, Okamoto M, Schymik G, Jacobshagen C, Rothe J, Treede H, Kerber S, Frank D, Bramlage P, Sykorova L, et al. Degree of valve calcification in patients undergoing transfemoral transcatheter aortic valve implantation with and without balloon aortic valvuloplasty: findings from the multicenter EASE-IT TF registry. Catheter Cardiovasc Interv. 2019. https://doi.org/10.1002/ ccd.28164. Epub ahead of print.

18. Bramlage P, Romano M, Bonaros N, Cocchieri R, Jagielak D, Frank D, Bapat V. Transaortic transcatheter aortic valve implantation - rationale and design of the multicenter, multinational prospective ROUTE registry. BMC CardiovasC Disord. 2014;14:152.

19. Butter C, Bramlage P, Rudolph T, Jacobshagen C, Rothe J, Treede H, Kerber S, Frank D, Seilerova L, Schymik G. Balloon expandable transcatheter aortic valve implantation via the transfemoral route with or without pre-dilation of the aortic valve - rationale and design of a multicentre registry (EASE-IT TF). BMC Cardiovasc Disord. 2016;16(1):223.

20. Bramlage P, Strauch J, Schrofel H. Balloon expandable transcatheter aortic valve implantation with or without pre-dilation of the aortic valve rationale and design of a multicenter registry (EASE-IT). BMC CardiovasC Disord. 2014;14:160

21. Kappetein AP, Head SJ, Genereux P, Piazza N, van Mieghem NM, Blackstone EH, Brott TG, Cohen DJ, Cutlip DE, van Es GA, et al. Updated standardized endpoint definitions for transcatheter aortic valve implantation: the valve academic research Consortium-2 consensus document (VARC-2). Eur J Cardiothorac Surg. 2012:42(5):S45-60

22. R Core Team. A language and environment for statistical computing. https://www.R-project.org/. Accessed 15 July 2019.

\section{Publisher's Note}

Springer Nature remains neutral with regard to jurisdictional claims in published maps and institutional affiliations.

Ready to submit your research? Choose BMC and benefit from:

- fast, convenient online submission

- thorough peer review by experienced researchers in your field

- rapid publication on acceptance

- support for research data, including large and complex data types

- gold Open Access which fosters wider collaboration and increased citations

- maximum visibility for your research: over $100 \mathrm{M}$ website views per year

At $\mathrm{BMC}$, research is always in progress.

Learn more biomedcentral.com/submissions 